\title{
Acessibilidade e capacidade para pagar pelos serviços de água e de esgotamento sanitário em Portugal
}

\section{Affordability and accessibility in the water and wastewater services in Portugal}

\author{
Pedro Carvalho \\ Mestre. Doutorando do Centro de Sistemas Urbanos e Regionais do Instituto Superior Técnico da Universidade Técnica de Lisboa (UTL) \\ Pedro Simões \\ Mestre. Doutorando do Centro de Sistemas Urbanos e Regionais do Instituto Superior Técnico da UTL \\ Rui Cunha Marques \\ Doutor. Professor do Centro de Sistemas Urbanos e Regionais do Instituto Superior Técnico da UTL
}

\section{Resumo}

O crescimento da população mundial no último século tem conduzido a um aumento exponencial do uso da água, a um consequente aumento da sua escassez, bem como a uma diminuição da sua qualidade. Uma das principais causas responsáveis por essa realidade tem sido o reduzido preço que os diferentes stakeholders pagam por esse recurso. O facto de não ser pago pelos diferentes stakeholders um preço justo que reflita os impactos causados no ambiente, bem como na vida das gerações futuras pelo consumo desse recurso, tem conduzido à sobre-exploração da água. Nesse contexto, perspectivase, em nível mundial, um incremento dos encargos com os serviços de águas e de esgotamento sanitário, com o intuito de tornar a gestão desse recurso sustentável e, paralelamente, melhorar a sua qualidade. Este trabalho compara os encargos que as famílias de vários países suportam com esses serviços e analisa, em detalhe, o impacto atual desses encargos nas famílias em Portugal, evidenciando os resultados de dois estudos recentes e das reformas em curso. Conclui-se que o aumento do preço do recurso água será inevitável e, por conseguinte, uma maior parcela dos rendimentos familiares será dispensada com esses serviços. Este trabalho demonstra que será no interior de Portugal que poderão surgir, no futuro, os maiores problemas de affordability.

Palavras-chave: rendimentos; encargos com os SAES; sistema tarifário; Portugal.

\section{Abstract}

The world population growth over the last century has led to an exponential increase in water use, besides more scarcity of this resource and a drop in its quality. One of the major failures in the water sector has been the low price that different stakeholders pay for this good. The fact that a fair price has not been paid for water reflects its overuse with impacts on the environment and on the lives of future generations. In this context, it is expected that the expenses with the water and wastewater services will rise all over the world in order to achieve a more sustainable management of this resource and improve its quality. This research makes a comparison between the costs that families from different countries have with these services and examines in detail the impact of these charges in Portuguese households, providing evidence of the results of two recent studies and ongoing reforms. We conclude that the increase in the price of water resources will be unavoidable and therefore a greater part of family income will be spent on these services. This work shows that the biggest problems of affordability which may come up in the future will occur in the countryside of Portugal.

Keywords: income; drinking water and wastewater services expenditures; tariffs; Portugal.

\section{Introdução}

O fornecimento de água com qualidade elevada e em quantidade adequada reveste-se de extrema importância para a salvaguarda da saúde humana e da qualidade de vida. Contudo, o crescimento da população mundial, sobretudo no último século, e o consequente aumento do consumo da água tem conduzido a uma diminuição da sua disponibilidade. Segundo a Comissão Mundial da Água (World Commission on Water), as necessidades de água aumentarão cerca de 50\% nos próximos 30 anos e cerca de 4 mil milhões de pessoas (metade da população mundial) viverão em situações muito desfavoráveis em termos de abastecimento de água, com condições particularmente críticas na África, no Médio Oriente e na Ásia Meridional (BANCO MUNDIAL, 2006). 
De acordo com o Relatório do Desenvolvimento Humano 2006 do Programa das Nações Unidas para o Desenvolvimento (PNUD, 2006), atualmente 1,1 mil milhões de pessoas têm um acesso inadequado ao serviço de água e 2,6 mil milhões de pessoas não dispõem do serviço de esgotamento sanitário. Cerca de 1,8 milhões de crianças morrem anualmente como consequência de diarreia e de outras doenças provocadas pela ingestão de água em deficientes condições. A ausência dessas infraestruturas resulta, assim, em impactos incalculáveis na saúde pública e na economia mundial. Para atenuar esse panorama, as Nações Unidas têm o objetivo de reduzir para a metade o número de pessoas sem acesso à água potável e ao esgotamento sanitário em 2015. Para além de todos os problemas referidos, verifica-se, ainda, uma exploração excessiva dos recursos hídricos em diversas regiões do mundo, situação com propensão para se agravar. De acordo com o mesmo relatório, atualmente, mais de 1,4 mil milhões de pessoas vivem em bacias hidrográficas onde a utilização de água excede os níveis mínimos de reposição, conduzindo à dissecação dos rios e ao esgotamento das águas subterrâneas.

Em Portugal, com a publicação da Lei da Água em 2005 (lei no 58, de 29 de dezembro), que transpõe para a ordem jurídica nacional a diretiva $n^{\circ}$ 2000/60/CE, do Parlamento Europeu e do Conselho, de 23 de outubro (conhecida como Diretiva-Quadro da Água), cujo objetivo é garantir uma utilização sustentável da água e evitar a degradação dos recursos, terão de ser garantidas a internalização dos custos decorrentes do uso da água bem como dos custos de escassez e dos custos relativos às atividades suscetíveis de causar um impacto negativo no estado de qualidade e quantidade das águas. A lei contempla também a necessidade de assegurar a recuperação dos custos dos serviços, promovendo a sustentabilidade dos operadores e a transparência no setor.

Perante esse cenário, é inevitável que os custos envolvidos na prestação dos serviços de abastecimento de água e dos serviços de coleta e tratamento de esgoto (daqui em diante: Serviços de Água e de Esgotamento Sanitário - SAES), que incluem não só os custos de operação e manutenção mas também os custos de capital (investimentos), sejam refletidos no valor das tarifas pagas pelos consumidores, o que pode tornar-se um problema sério para a população mais desfavorecida não apenas em Portugal, mas também em muitos outros países, visto que terão de gastar uma quota-parte relevante dos seus rendimentos.

Este estudo avaliou a capacidade para pagar dos usuários (conhecida na literatura anglo-saxónica pelo termo affordability) e o impacto dos encargos com os SAES, isto é, dos montantes a pagar por esses serviços nos rendimentos das famílias portuguesas, bem como avaliar a sua disponibilidade para pagar mais em compensação da garantia de serviços de melhor qualidade. Complementarmente, examina-se o impacto no orçamento familiar, caso o pagamento dos SAES fosse o adequado e analisa-se brevemente a situação internacional. Embora a espinha dorsal deste trabalho seja essencialmente descritiva, procurase, sempre que possível, efetuar uma análise do impacto regulatório do aumento das tarifas, sobretudo nos usuários com maior dificuldade em suportar o custo da prestação desses serviços.
Para a avaliação da parcela dos rendimentos familiares gasta com o usufruto da prestação dos SAES em Portugal, foram utilizados dados disponibilizados pelo Instituto Regulador de Águas e Resíduos (IRAR) e pelo Instituto Nacional de Estatística (INE). A estimativa da parcela do orçamento das famílias destinada aos SAES permitirá avaliar a affordability das famílias para referidos serviços. Para além desta breve introdução, o remanescente do artigo segue apresentando o setor da água em Portugal. De seguida, abordam-se alguns estudos de affordability em vários países, designadamente na Itália, Inglaterra e País de Gales, Estados Unidos da América e Canadá. Posteriormente, são evidenciados dois estudos efetuados em Portugal sobre esta matéria e a metodologia adotada para analisar a problemática da affordability em Portugal. A última seção apresenta as principais conclusões do estudo

\section{Setor da água em Portugal}

Até meados do século 20, as massas de água em Portugal foram muitas vezes utilizadas sem ser considerada a sua capacidade de regeneração, conduzindo à sobre-exploração de alguns aquíferos e rios e à degradação da qualidade das águas superficiais (IRAR, 2007a).

A entrada de Portugal na Comunidade Económica Europeia, em 1986, veio dotar o país de meios financeiros para a realização de investimentos no setor da água e possibilitar uma alteração de estratégia, e, assim, alcançar melhores níveis de cobertura e de qualidade de serviço prestado aos cidadãos. Em 1993, com a publicação de duas leis, o decreto-lei $n^{\circ}$ 372/93, de 29 de outubro, e o decreto-lei no 379/93, de 5 de novembro, passou a ser permitida a participação de entidades privadas na gestão e exploração dos SAES. Esses documentos normativos vieram também facultar a criação de sistemas integrados envolvendo vários municípios, denominados de sistemas multimunicipais (sistemas em "alta"), permitindo, por conseguinte, a geração de economias de escala e de otimização dos sistemas. A classificação de sistemas em "alta" e "baixa" surge durante a criação desses sistemas multimunicipais. Essas designações correspondem, respectivamente, às atividades grossista e retalhista dos setores de abastecimento de água e de esgotamento sanitário. No setor de abastecimento de água, a componente em "alta" corresponde, assim, às atividades desde a captação até o armazenamento (reservatórios) e que englobam as atividades de transporte e tratamento de água potável, ao passo que água a componente em "baixa" engloba as atividades de armazenamento de distribuição ao consumidor. No setor do esgotamento sanitário, a componente em "alta" corresponde às atividades de tratamento, transporte e descarga do esgoto no meio receptor, enquanto a componente em "baixa" corresponde às atividades de drenagem e coleta de esgoto urbano. É nessa altura que é constituída a empresa pública Águas de Portugal (AdP). Em 1997, foi criado o IRAR, tendo como missão regular os SAES (e os resíduos) em Portugal, cuja atividade teve início em 2000. Suas responsabilidades consistem em assegurar a qualidade 
dos serviços prestados pelos sistemas multimunicipais e municipais, supervisionando a concepção, execução, gestão e exploração dos sistemas, bem como a garantia do equilíbrio do setor e a sustentabilidade econômica desses sistemas. Contudo, nem todos os SAES ficaram sujeitos à sua intervenção, como é o caso das entidades de administração local autárquica (serviços municipais e municipalizados), sobre as quais o IRAR atua apenas no âmbito do controle da qualidade da água para consumo humano. Uma das funções mais importantes do IRAR consiste na aplicação da denominada regulação sunshine, isto é, na aplicação e comparação do desempenho (benchmarking) dos operadores e da sua discussão pública (MARQUES, 2008; MARQUES; SIMÕES, 2008).

As dificuldades reveladas pelos municípios no cumprimento de prazos para a realização eficaz dos projetos financiados pelo Fundo de Coesão levaram o Governo a definir, em 1999, por meio do Plano Estratégico de Abastecimento de Água e de Saneamento de Águas Residuais (PEAASAR) 2000-2006, um conjunto de orientações estratégicas com o objetivo de melhorar a cobertura e o funcionamento dos SAES no País. O PEAASAR veio reforçar a promoção de soluções integradas, a ampliação dos sistemas existentes, a realização de novos sistemas, a promoção da qualidade das origens de água, a adequação e a reabilitação de estações de tratamento, a redução de perdas de água e a reutilização do esgoto tratado. Decorrido esse período, verificouse que, apesar dos progressos alcançados, questões importantes permaneciam por resolver, tornando necessária a reformulação da estratégia adotada no passado, designadamente porque se constatou uma grande desarticulação entre os sistemas em "alta" e em "baixa". Assim, foi elaborado um novo plano, o PEAASAR II, para o período 20072013. Esse plano define três grandes objetivos estratégicos e respectivas orientações, designadamente, a universalidade, a continuidade e a qualidade do serviço, a sustentabilidade do setor, implicando a melhoria da produtividade e da eficiência e a proteção dos valores ambientais. Como objetivos operacionais, pretende-se servir cerca de 95\% da população com sistemas públicos de abastecimento de água e cerca de $90 \%$ da população total do país com sistemas públicos de esgotamento sanitário. Com o PEAASAR II, pretende-se: a realização de investimentos necessários à conclusão e expansão dos sistemas em "alta", assim como a sua articulação com a "baixa"; a definição dos critérios de elegibilidade aos fundos estruturais; a revisão dos princípios de enquadramento legal, técnico, econômico e financeiro dos sistemas; a implementação das disposições da legislação relacionadas com o setor e o estímulo aos modelos de financiamento que potenciem o investimento privado e promovam a concorrência no setor. A concretização desse segundo plano compreenderá um investimento de 4 mil milhões de euros. Para a conclusão dos sistemas em "baixa" e sua articulação com os sistemas em "alta", serão necessários investimentos da ordem de 2,2 mil milhões de euros e para os sistemas em "alta", os investimentos ascenderão a 1,6 mil milhões de euros destinados à conclusão e expansão dos sistemas multimunicipais (IRAR, 2007a).
No final do ano 2005, com a publicação da Lei da Água, foi transposto para o direito interno a Directiva Quadro da Água. Esta, além de estabelecer as bases para a gestão sustentável das águas, define o quadro institucional para essa gestão, nomeadamente por meio da harmonização com o princípio da região hidrográfica como unidade principal de planejamento e gestão, criando cinco Administrações de Região Hidrográfica (ARH). Essa lei estabelece o enquadramento para a gestão das águas superficiais, designadamente as águas interiores, de transição e costeiras e as águas subterrâneas, de forma a assegurar uma utilização sustentável, evitar a degradação dos recursos e garantir a proteção destes a longo prazo. Além disso, essa lei inclui também a alteração ao regime econômico-financeiro aplicável à utilização das águas, do qual provém a necessidade de assegurar a internalização dos custos decorrentes das atividades suscetíveis de causar um impacto negativo no estado de qualidade e quantidade das águas e também a certeza da recuperação dos custos das prestações públicas que proporcionem vantagens aos usuários ou garantam a qualidade e a quantidade das águas utilizadas, incluindo-se aqui os custos de escassez.

Atualmente, o setor da água em Portugal é caracterizado por um elevado número de SAES no sistema em "baixa" (cerca de 300, na sua grande maioria geridas pelos próprios municípios, por intermédio de serviços municipais) e, por vezes, por uma certa desarticulação entre os sistemas em "alta" e os sistemas em "baixa" (MARQUES, 2005). Nos sistemas em "alta", as entidades gestoras concessionárias de sistemas multimunicipais são controladas maioritariamente (mais de 70\%) pela AdP, estando o restante do capital social na alçada dos municípios dos respectivos sistemas. A Empresa Portuguesa das Águas Livres S. A. (EPAL) e a Águas de Santo André compreendem modelos atípicos, na medida em que prestam serviços em "alta" e em "baixa" em sistemas multimunicipais, pertencendo, na sua totalidade, à empresa das AdP.

O nível de cobertura da população com serviços de abastecimento público de água era de cerca de 93\%, no final de 2005, valor muito próximo da média dos países da União Europeia. O volume de água captada foi de, aproximadamente, 950 milhões de $\mathrm{m}^{3}$ em 2005, dos quais mais de metade foi distribuída nos distritos de Lisboa, Porto e Setúbal. O volume faturado foi de cerca de 600 milhões de $\mathrm{m}^{3}$, ao que poderá corresponder um volume de perdas de água de 30\% (MARQUES; LEVY, 2006). Do volume faturado, 66\% foi disponibilizado a consumidores domésticos e 17\% a consumidores industriais e comerciais. Do volume total captado, cerca de 2/3 foram de origem superficial e 1/3 de origem subterrânea. Estima-se, para todos os sistemas de abastecimento de água portugueses, em "alta" e "baixa", um património superior a 5 mil milhões de euros. Em 2005, os custos do serviço de abastecimento de água em "baixa" foram de cerca de 840 milhões de euros e os proveitos, ligeiramente superiores (MARQUES; LEVY, 2006). O investimento acumulado no segmento concessionádo dos SAES, medido pelo imobilizado bruto, totalizava 4,4 mil milhões de euros em 2006 (IRAR, 2007a). 


\section{Revisão de estudos de affordability}

\section{Nota introdutória}

Apresentam-se, de seguida, exemplos de estudos sobre a problemática da affordability em cinco países disitintos, designadamente na Itália, Inglaterra e País de Gales, Estados Unidos e Canadá. Não obstante existam outros estudos sobre outros países na literatura sobre esse assunto (SMETS, 2008; FANKHAUSER; TEPIC, 2007), adotaram-se esses países, por um lado, pela sua importância no contexto mundial e, por outro lado, por constituírem diferentes modelos de governo, incluindo gestão pública e privada e gestão municipal e supramunicipal (regional), o que, a priori, poderá, pela sua diversidade, enriquecer as conclusões do leitor.

\section{Affordability na Itália}

Com a reestruturação do setor da água em Itália (Lei "Galli"), os serviços municipais foram agregados em áreas territoriais ótimas (Ambito Territoriale Ottimale - ATO), passando de vários milhares de operadores para cerca de uma centena (DANESI; PASSARELLI; PERUZZI, 2007).

Essa reforma permitiu explorar o crescimento de economias de escala e de escopo, mas em simultâneo, exigiu o aumento do investimento que, para ser realizado, levou o Poder Público a promover a participação do setor privado na gestão dos serviços e a aumentar os seus sistemas tarifários, com consequências diretas no rendimento dos consumidores, em especial no das famílias mais carenciadas.

A Itália enfrenta atualmente problemas graves nas infraestruturas dos SAES, desde as elevadas perdas de água na rede de abastecimento (cerca de 42\%) até extravasamentos da rede de esgotos. Para garantir uma elevada qualidade dos serviços, serão necessários investimentos vultuosos nas próximas décadas, isto é, cerca de 51 mil milhões de euros entre 2000 e 2026 (47,6 mil milhões, tendo-se em conta a paridade do poder de compra - PPP), ao que corresponde a um investimento médio anual de $33 €$ por habitante por ano. Esse montante, ainda assim, é bem inferior ao estimado para outros países, como é o caso do Reino Unido e dos Estados Unidos, nos quais se prevêem investimentos médios anuais da ordem de $79 €$ por habitante para o período 2005-2010 e de 74€ por habitante para o período 20002019, respectivamente (DANESI; PASSARELLI; PERUZZI, 2007).

Antes da ocorrência da reforma, a despesa média das famílias com os SAES representava 0,70\% dos seus rendimentos, passando para $0,84 \%$ depois da sua implementação, correspondendo a um aumento de $21 \%$. Para as famílias com rendimentos médios mais baixos, o acréscimo foi de 1,27\% antes da reforma para 1,54\% após a reforma. Os resultados são superiores para as famílias que se encontram abaixo da linha de pobreza relativa (1,97 a 2,38\%) e ainda piores para aquelas que se encontram abaixo da linha de pobreza absoluta, aumentando de 2,81\% antes da reforma para 3,40\% após a reforma, podendo atingir os 5,06\% (DANESI; PASSARELLI; PERUZZI, 2007).

Prevê-se que na Itália os custos com os SAES representem 1,09\% dos rendimentos médios familiares no ano 2017-2018, colocando o país próximo dos valores mínimos referidos pela Organização para a Cooperação e Desenvolvimento Económico (OCDE), que são de 0,5 a 2,4\% (OCDE, 2002). Se se considerarem os rendimentos familiares mais baixos, crê-se que os custos com os SAES representem 1,99\% desses rendimentos em 2017-2018, uma percentagem inferior às consideradas pela OCDE (2,3-3,9\%). Por outro lado, para as famílias que se encontram abaixo da linha de pobreza relativa, essas percentagens poderão atingir os 2,99\% para o mesmo período, agravando-se ainda mais o panorama se forem considerados os rendimentos das famílias abaixo da linha de pobreza absoluta, podendo essa percentagem elevar-se de 3,40\% (período 1999-2002) para 4,35\% (com um mínimo de 2,61\% e um máximo de 5,99\%).

\section{Affordability na Inglaterra e no País de Gales}

De acordo com um estudo governamental recente, o peso das tarifas de água no rendimento médio das famílias diminuiu no período de 1999-2004 na Inglaterra e País de Gales (DEFRA, 2004). No entanto, segundo o regulador de Inglaterra e País de Gales dedicado ao setor da água (The Water Services Regulation Authority - OFWAT), este tende a aumentar no período regulatório atual, isto é, entre 2008 e 2013.

Para os consumidores com rendimentos médios e mais elevados, as despesas com os SAES representam uma pequena parcela dos seus rendimentos; no entanto, para os consumidores com mais baixos rendimentos, como é o caso daqueles que usufruem de salários reduzidos, dos desempregados e dos pensionistas, a affordability poderá tornar-se uma preocupação séria (DEFRA, 2004). Segundo o mesmo estudo, em 2004-2005, as famílias residentes em South West, que são as que evidenciam rendimentos mais baixos, gastaram uma parcela elevada (cerca de 3,2\%) dos seus rendimentos com os SAES, atingindo, mesmo em alguns casos, 6,5\%.

O referido estudo prevê para a Inglaterra e para o País de Gales um aumento das despesas dos consumidores com os SAES no futuro, o que poderá representar 2,6\% dos rendimentos mais baixos em 2009 e 2010, mantendo-se em cerca de 0,5\% para os consumidores com rendimentos mais elevados.

Embora o estudo da DEFRA efetue algumas recomendações que conduzirão a melhores condições de affordability para os grupos de consumidores mais desfavorecidos, refira-se que, nesse domínio, existem várias políticas sociais implementadas, por exemplo, a proibição do desligamento do serviço de água por falta de pagamento para os consumidores mais desfavorecidos ou com necessidades especiais. Essas medidas são de particular relevo, tendo-se em consideração que todos os operadores são privados. 
Affordability nos Estados Unidos

Nos Estados Unidos, a affordability foi investigada pelo Congressional Budget Office (CBO) em 2002 (CBO, 2002). De acordo com o estudo efetuado no final dos anos 1990, o custo dos SAES representava $0,5 \%$ do rendimento médio das famílias. Porém, para as famílias com rendimentos mais baixos, esse valor atingiu 2,5\% dos montantes auferidos. O CBO analisou o impacto que teria uma nova tarifa capaz de financiar os investimentos futuros necessários nos rendimentos das famílias e concluiu que, em 2019, os encargos médios dos SAES variariam entre 0,6 e 0,9\% dos rendimentos das famílias.

Segundo o CBO, no final dos anos 1990, 7\% dos consumidores gastavam mais de $4 \%$ dos seus rendimentos com os SAES, e esse valor tenderá a aumentar para valores compreendidos entre 10 e 20\% em 2019. O estudo termina defendendo que as famílias com menores rendimentos, que tenham dificuldade para pagar as suas contas de SAES, devem ser apoiadas pelos fundos resultantes das novas tarifas.

\section{Avaliação da percepção da qualidade de água dos serviços no Canadá}

Recentemente, no Canadá foi também realizado um estudo com o objetivo de investigar a percepção dos consumidores em relação à qualidade de água dos serviços na cidade de Hamilton, Ontário, e também se procurou perceber os principais motivos porque se recorre frequentemente ao uso alternativo da água da rede, como o recurso à água engarrafada e ao tratamento em casa, através de equipamentos individuais. A pesquisa envolveu a coleta de opiniões de uma amostra representativa.

De acordo com esse estudo, em geral, os participantes expressam pontos de vista negativos em relação à água da rede (JONES et al., 2007). Uns justificam a escolha da água engarrafada, considerando que esta é superior no sabor e na segurança, enquanto outros a usam meramente por conveniência ou conforto. Alguns participantes empregam, ainda, equipamentos de tratamento de água em casa, afirmando que se sentem mais seguros em relação à água que ingerem. No entanto, segundo o mesmo estudo, os equipamentos de tratamento, por vezes, não fornecem a proteção que a população julga adequada. Por exemplo, alguns equipamentos utilizam filtração por carbono ativo, técnica que deveria ser usada apenas com água segura microbiologicamente. Além disso, a falta de manutenção e o uso incorreto dos equipamentos de tratamento podem originar uma água quimicamente mais pobre e de pior qualidade microbiológica do que a própria água da rede.

A percepção negativa da água do sistema público de abastecimento deve-se, muitas vezes, à intensa publicidade. Alguns participantes comentam que o marketing relativo tanto à água engarrafada como aos equipamentos de tratamento de água tem influência na apreensão da população no que concerne à água da rede, podendo até transmitir receios de segurança aos consumidores (JONES et al., 2007).
O estudo refere ainda que a melhor gestão dos SAES - manifestada, por exemplo, por meio da proteção das origens de água, da manutenção ou melhoria dos processos de tratamento, dos testes de qualidade da água e do próprio sistema de distribuição - pode conduzir a progressos na percepção dos consumidores em relação à qualidade da água que é fornecida. Por último, esse documento realça também que os consumidores desejam mais informação e divulgação em relação aos testes de qualidade de água, bem como aos processos de tratamento utilizados, à sua eficácia e aos riscos para a saúde pública que podem persistir após o tratamento, desejando também uma linguagem clara e perceptível para todos.

\section{Inquéritos efetuados em Portugal}

Um estudo efetuado recentemente pela Associação das Empresas Portuguesas para o Sector do Ambiente (AEPSA), que teve como base dois inquéritos promovidos por essa associação, demonstrou que, em 2005, a generalidade dos consumidores em Portugal manifestava pouca disponibilidade para pagar mais pela água, mesmo que esse contributo adicional se destinasse a uma melhor qualidade de serviço (MARQUES; LEVY, 2006). Apenas 15\% dos consumidores admitiram essa possibilidade. Posteriormente, um outro estudo desenvolvido pelo IRAR, em dezembro de 2007, veio corroborar os resultados anteriores, o qual constatou uma resistência significativa, manifestada por $70 \%$ dos inquiridos, a pagar mais como contrapartida de um elevado nível de qualidade dos SAES (IRAR, 2007b).

O estudo desenvolvido pela AEPSA revela também que a percepção sobre a qualidade da água e do seu abastecimento melhorou significativamente de 1996 para 2005 e que, embora persistam problemas pontuais de qualidade da água e de falta de água ou de pressão, a maioria dos consumidores está satisfeita com a qualidade dos serviços. No entanto, observou-se também um aumento do número de consumidores a recorrer à água engarrafada, o que parece contraditório com o fato anterior. Esse documento apresenta duas razões como justificação dessa circunstância. Uma delas está relacionada com a melhoria do nível de vida da população portuguesa observada nesse período, o que proporcionou um acesso mais fácil ao consumo de água engarrafa. A outra razão está associada ao fato de as entidades gestoras não terem conseguido diminuir a informação assimétrica, persistindo, assim, a falta de confiança dos consumidores em relação às entidades gestoras, apesar de várias entidades certificarem a qualidade da água fornecida (por exemplo, IRAR).

De acordo com a investigação realizada pelo IRAR, os principais motivos que levam os consumidores a recusar pagar mais por uma melhor qualidade de serviço são principalmente reflexo do seu descontentamento perante a ação do Estado. Por um lado, apontam que pagam demasiados impostos, atribuindo ao Estado a responsabilidade de assegurar os serviços essenciais, e que o seu contributo já é suficiente para lhes ser concedido um serviço de qualidade; por outro lado, não acreditam que os eventuais contributos adicionais pagos sejam, de fato, traduzidos na prestação de uma melhor qualidade dos serviços. 
O fato de o valor médio da fatura ter vindo a aumentar - conjuntamente com a falta de informação e a desatenção que os consumidores evidenciam em relação aos progressos positivos conquistados no setor - pode estar também na base desses protestos. Além disso, há que não esquecer que essa baixa disponibilidade para pagar é usual no fornecimento de bens públicos. O comportamento dos usuários perante a disposição para pagar o fornecimento de bens públicos é estratégico em função da ocasião. Antes da prestação do serviço, manifestam grandes necessidades de consumo/utilização e vontade de pagar, depois revelam consumo reduzido e pouca disponibilidade para pagar, constrangendo também os outros usuários a fazê-lo (MARQUES, 2005).

Ainda de acordo com o estudo desenvolvido pelo IRAR, os fatores que mais influenciam a disponibilidade para pagar são a educação, o rendimento, a juventude e a atitude ambiental. Com efeito, quase metade dos entrevistados com nível de ensino superior estão dispostos a pagar um valor adicional por uma melhor qualidade dos serviços, e semelhante percentagem se verifica entre os entrevistados com maiores rendimentos. Os entrevistados mais jovens também manifestam maior disposição para pagar, provavelmente por essas gerações terem sido mais sensibilizadas para as questões ambientais.

\section{Metodologia}

Com o objetivo de estimar a parcela dos rendimentos que as famílias gastam para usufruir da prestação dos SAES em Portugal, foram adotados, no presente trabalho, dados disponibilizados pelo IRAR e pelo INE.

Os dados relativos às despesas anuais dos agregados familiares com os SAES, verificadas em 2004, foram disponibilizados pelo IRAR, os quais correspondem a usuários domésticos com consumos anuais de $200 \mathrm{~m}^{3}$ de água da rede de abastecimento pública. Essa informação é relativa a sistemas municipais e teve como base a informação constante da publicação "Água e Saneamento em Portugal - o mercado e os preços 2006" (APDA, 2006) desenvolvida pela Comissão Especializada de Legislação e Economia da Associação Portuguesa de Distribuição e Drenagem de Águas (APDA). Essa associação reúne todas as entidades gestoras dos SAES, tanto de Portugal Continental como das ilhas (correspondentes às regiões autónomas dos Arquipélagos da Madeira e dos Açores), englobando, como tal, todos os 308 municípios de Portugal.

Os rendimentos anuais médios por agregado familiar foram disponibilizados pelo INE (2008). Esses dados correspondem aos rendimentos anuais médios por agregado familiar observados nos anos $2005 \mathrm{e}$ 2006 pela Nomenclatura Comum das Unidades Territoriais Estatísticas de Nível II (NUTSII), tendo sido convertidos para o ano 2004, a partir do Índice de Preços no Consumidor (IPC) verificado em dezembro de 2004, excluindo-se a parcela correspondente à habitação.

$\mathrm{Na}$ elaboração dos gráficos das figuras apresentadas na seção seguinte foi também usada informação cartográfica disponibilizada pela Agência Portuguesa do Ambiente (APA). Os gráficos das figuras foram conseguidos com o apoio de um software de Sistema de Informação Geográfica (SIG) - tendo como suporte a informação cartográfica referida anteriormente, nomeadamente, a delimitação dos municípios e do país - e foram desenvolvidos pelos autores deste estudo.

\section{Affordability em Portugal}

Em Portugal, a generalidade das tarifas praticadas pelos SAES não repercutem sobre os consumidores o custo real de provisão do serviço nem promovem o uso eficiente do recurso água. Deve-se salientar que em Portugal continental, em 2004, 78 municípios (cerca de 25\%) não cobravam qualquer valor pelo serviço de esgotamento sanitário e que $73 \%$ dos serviços apenas cobravam um valor inferior ou igual a $50 €$ por ano pelo serviço de coleta e tratamento de esgoto (Figura 1), o que poderá ser insustentável, visto que, em termos médios, esses serviços têm custos da mesma ordem de grandeza ou mesmo superiores aos do serviço de abastecimento de água. Esse panorama leva os operadores a desinvestir ou a realizar apenas os investimentos críticos por falta de capacidade, o que, a médio e longo prazo, resultará na degradação das infraestruturas e na deterioração da qualidade de serviço. Por sua vez, os consumidores não têm incentivos para realizar uma gestão eficiente da água. Note-se que essa perspectiva empresarial ou de autossustentabilidade poderá ser discutida e terá de o ser forçosamente em muitos países. No entanto, em Portugal, com a Lei da Água (dando cumprimento à legislação da União Europeia e, em particular, à Directiva-Quadro da Água), o panorama de falta de sustentabilidade econômico-financeira terá de ser alterado num futuro próximo. A referida lei estabelece as bases para a gestão sustentável da água, referindo que os preços dos SAES devem respeitar os princípios do valor social, da dimensão ambiental e do valor econômico da água. Assim, além de assegurarem a recuperação dos custos de investimento e de operação dos serviços, as futuras tarifas terão ainda de incorporar uma componente relativa às taxas de utilização dos recursos hídricos, com o objetivo de internalizar os custos ambientais e de escassez. Desse modo, no cumprimento estrito da lei, avizinha-se o aumento do preço desse recurso e, consequentemente, o aumento da parcela dos rendimentos familiares a desembolsar com os SAES. A Figura 1 ilustra as despesas com o serviço de esgotamento sanitário no ano 2004, por município, para usuários domésticos com um consumo de $200 \mathrm{~m}^{3}$ de água da rede pública.

Em 2004, as famílias portuguesas gastaram em média 173,26€ por ano com os SAES, isto é, $0,87 \%$ dos seus rendimentos, valor muito próximo do verificado na Itália após a introdução da reforma (0,84\%), mas superior ao registado nos Estados Unidos no final da década de 1990 (0,5\%) e inferior ao verificado em Inglaterra e no País de Gales em 2004/2005 (1,02\%), embora dentro do intervalo de valores recomendados pela OCDE (0,5 a 2,4\%). As Figuras 2 e 3 ilustram, respectivamente, as despesas com os SAES no ano 2004, por município, para usuários domésticos com um consumo de água de $200 \mathrm{~m}^{3}$ em valor absoluto e em percentagem 


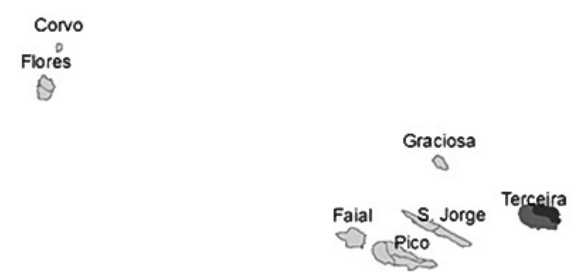

$\square 0,00 €-25,00 €$

$\square 25,01 € \cdot 50,00 €$

$50,01 €-75,00 €$

$75,01 €-100,00 €$

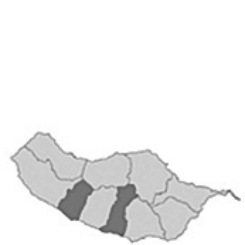

$0,00 €-25,00 €$

$25,01 €-50,00 €$

$50,01 €-75,00 €$
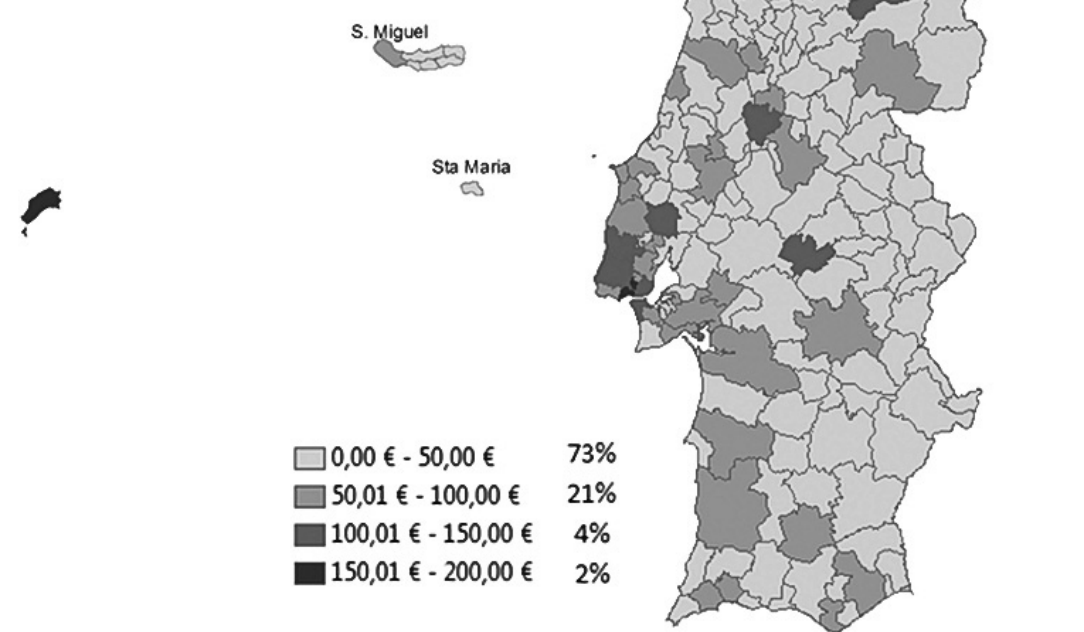

Figura 1 - Despesas com o serviço de esgotamento sanitário para os usuários domésticos por município (ano 2004).
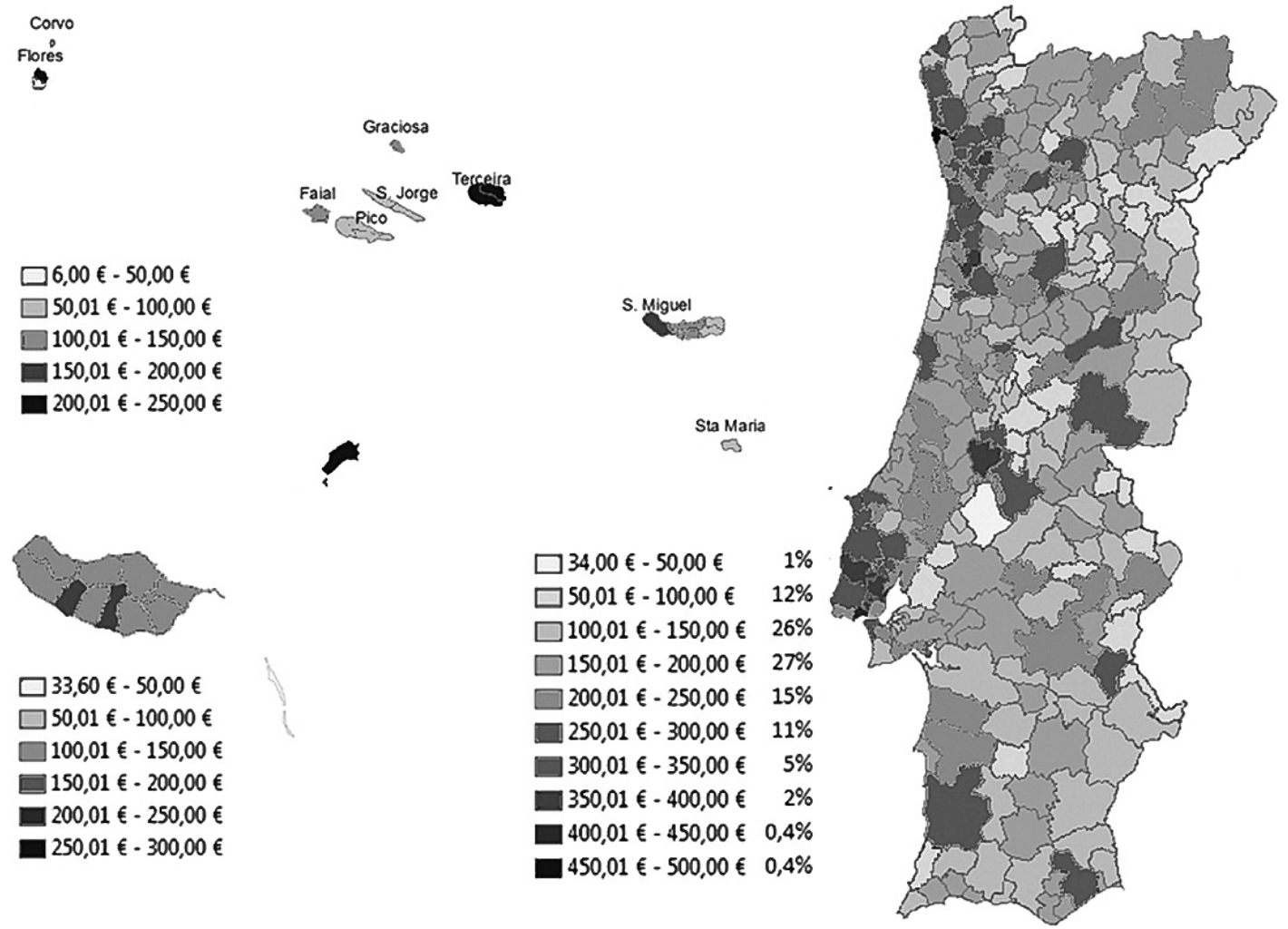

Figura 2 - Despesas com os Serviços de Água e de Esgotamento Sanitário para os usuários domésticos por município (ano de 2004). 
dos rendimentos líquidos anuais médios das famílias portuguesas. Dos 0,87\% do rendimento das famílias gasto, 0,70\% diz respeito aos serviços de abastecimento de água e 0,17\% aos serviços de esgotamento sanitário. O valor mais elevado, 2,52\%, ocorreu no município de Póvoa de Varzim (região Norte - Grande Porto) e o valor mais baixo, 0,03\%, verificou-se no município do Corvo (Região Autónoma dos Açores). As percentagens mais elevadas registaram-se nas regiões Norte, Lisboa e Centro e, em geral, nos municípios situados no litoral, correspondendo a uma média de 1,03\% do rendimento médio das famílias à região Norte, 0,94\% a Lisboa e $0,91 \%$ à região Centro. Os rendimentos mencionados equivalem aos rendimentos líquidos anuais médios das famílias do ano de 2004.

Se em vez dos rendimentos líquidos médios se considerarem os rendimentos disponíveis brutos das famílias do ano de 2004, conclui-se que, em média, 0,69\% do rendimento bruto disponível das famílias foi gasto com os SAES, correspondendo às percentagens médias mais elevadas e mais reduzidas, uma vez mais, ao município da Póvoa de Varzim (2,02\%) e ao município do Corvo (0,02\%), respectivamente. As percentagens médias mais elevadas verificaram-se também nas regiões Norte (0,83\%), Lisboa $(0,77 \%)$ e Centro $(0,73 \%)$.

Porém, ao observarem-se os rendimentos das famílias de menores recursos, a percentagem dos rendimentos destinados aos SAES aumenta consideravelmente. Se forem tomados os rendimentos iguais ao salário mínimo nacional, infere-se uma média nacional de 3,39\% em 2004; no entanto, ainda dentro do intervalo de valores referidos pela
OCDE (2,3-3,9\%) como moderados. Por exemplo, se for considerada uma família do município da Póvoa de Varzim com um rendimento igual ao Salário Mínimo Nacional, que era, em 2004, de 365,6€ mensais, alcança-se uma percentagem máxima de 9,57\% do rendimento gastos com os SAES, o que é muito elevado quando comparado com o valor máximo obtido em Inglaterra e no País de Gales, que era de 6,5\% em 2004-2005 para o caso de um pensionista a viver só com um rendimento igual à pensão mínima. A Figura 4 evidencia a percentagem das despesas com os SAES das famílias portuguesas com um rendimento igual ao salário mínimo nacional em 2004.

O quadro agrava-se ainda mais se forem consideradas as famílias com rendimentos líquidos médios constituídos apenas por pensões, situação a que corresponde uma média nacional de 4,87\% dos referidos rendimentos. No município da Póvoa de Varzim, verificou-se, mais uma vez, a percentagem mais elevada de $15,74 \%$ dos rendimentos, valor muito elevado face aos verificados nos países analisados. Para esses rendimentos familiares, apenas nas regiões Norte e Lisboa verificam-se valores médios acima da média, com 6,45 e 4,95\%, respectivamente.

Para os agregados familiares constituídos apenas por um idoso com um rendimento líquido anual de 9.144€, observou-se que, em 2004, gastaram com os SAES uma percentagem média de 1,89\% dos seus rendimentos, percentagens superiores às registadas em Itália (1,27\% antes da reforma (2002) e 1,54\% após a reforma), mas inferior à verificada em Inglaterra e no País de Gales em 2004-2005 (que foi de 3,2\%) e

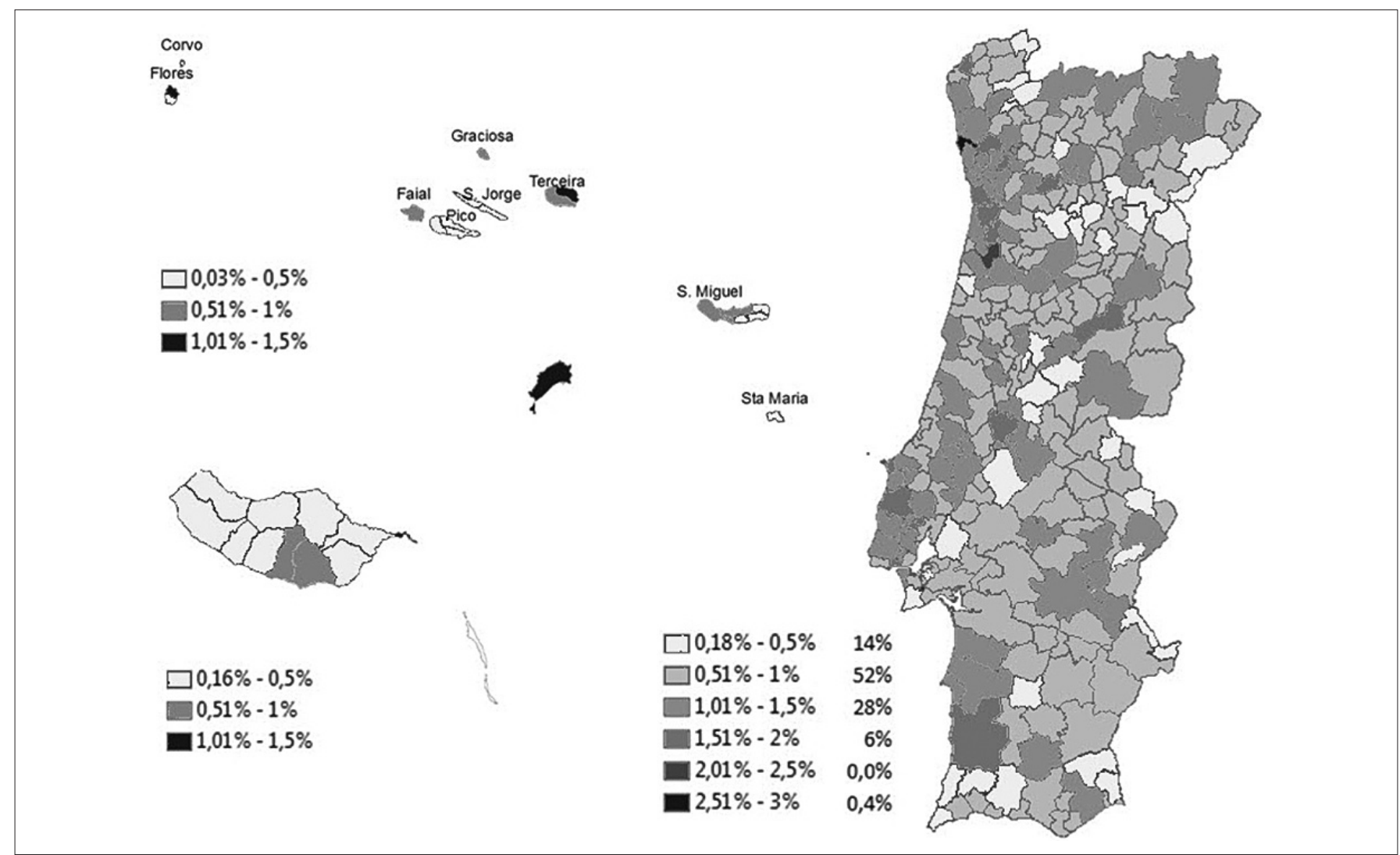

Figura 3 - Rendimentos líquidos das famílias portuguesas gastos com os Serviços de Água e de Esgotamento Sanitário por município em 2004. 
nos Estados Unidos (2,49\% nos finais de 1990). O valor máximo foi, uma vez mais, atingido no município da Póvoa de Varzim $(5,36 \%)$ e, embora elevado, é inferior ao valor observado para algumas famílias com mais baixos rendimentos em Inglaterra e no País de Gales em 2004-2005 $(6,5 \%)$. As regiões onde se apuraram as percentagens médias mais elevadas foram Lisboa (2,75\%), Norte (2,20\%) e Centro (1,95\%). A Figura 5 apresenta a percentagem de rendimentos dos agregados familiares constituídos apenas por um idoso gastos com os SAES.

Resultados semelhantes foram obtidos quando se examinaram o primeiro decil e o primeiro quintil dos rendimentos anuais líquidos dos agregados familiares, aos quais correspondem rendimentos anuais líquidos de 6.497,1€ e 8.112,0€, respectivamente. Em relação ao primeiro decil, inferiu-se que os agregados familiares gastaram 2,67\% dos seus rendimentos (com um máximo de 7,54\%) com os SAES e 2,14\% (com um máximo de 6,04\%) dos seus rendimentos quando se tem em conta o primeiro quintil dos rendimentos anuais líquidos dos agregados familiares. Embora elevados, esses valores médios encontram-se dentro dos limites moderados estabelecidos pela OCDE (2,3-3,9\%).

Por outro lado, verifica-se também que, em geral, nas regiões onde as famílias gastam mais dos seus rendimentos com os SAES, o poder de compra é superior, correspondente, sobretudo, aos municípios do litoral do país (Figura 6). Por sua vez, nos municípios do interior, as famílias gastam uma menor percentagem dos seus rendimentos com os SAES e o poder de compra é, em geral, mais baixo.
A Figura 6 evidencia o poder de compra médio em 2004 para os municípios (regiões NUTS II).

De acordo com os resultados de um inquérito realizado pelo INE (2008), um agregado familiar em Portugal gasta, em média, por ano, menos de um terço com as faturas da água (192€) do que com a eletricidade e gás (682 €) e com comunicações (519 €). As faturas da água representam uma percentagem de 1,1\% das despesas dos agregados familiares, ao passo que a eletricidade e gás representam 3,8\% e as comunicações, 3\%. O grupo das comunicações engloba os serviços postais, equipamentos de telecomunicação, serviços de telefone, telégrafo e telefax. A Figura 7 ilustra a despesa total anual média por agregado por NUTS II, no ano 2005-2006, com as faturas da água, eletricidade, gás e comunicações e as correspondentes percentagens.

A maior parcela das despesas dos agregados familiares é destinada às comunicações ( $519 €$, ou seja, 3,0\%), seguindo-se a eletricidade $(464 € / 2,6 \%)$, o gás $(218 € / 1,2 \%)$ e, por fim, a distribuição de água (153€/0,9\%), a recolha de resíduos sólidos (20 €/0,1\%) e os serviços de esgotamento sanitário (19 €/0,1\%) (Figura 7). Apesar de as despesas médias por agregado serem superiores à média nacional na região de Lisboa e inferiores no Alentejo (Figura 7), as percentagens das despesas dos agregados familiares, essencialmente as despesas de eletricidade e gás, são inferiores à média nacional na região de Lisboa e superiores no Alentejo (Figura 7), o que pode dever-se ao fato de na região de Lisboa se gastar mais em outros bens e serviços (como é o caso

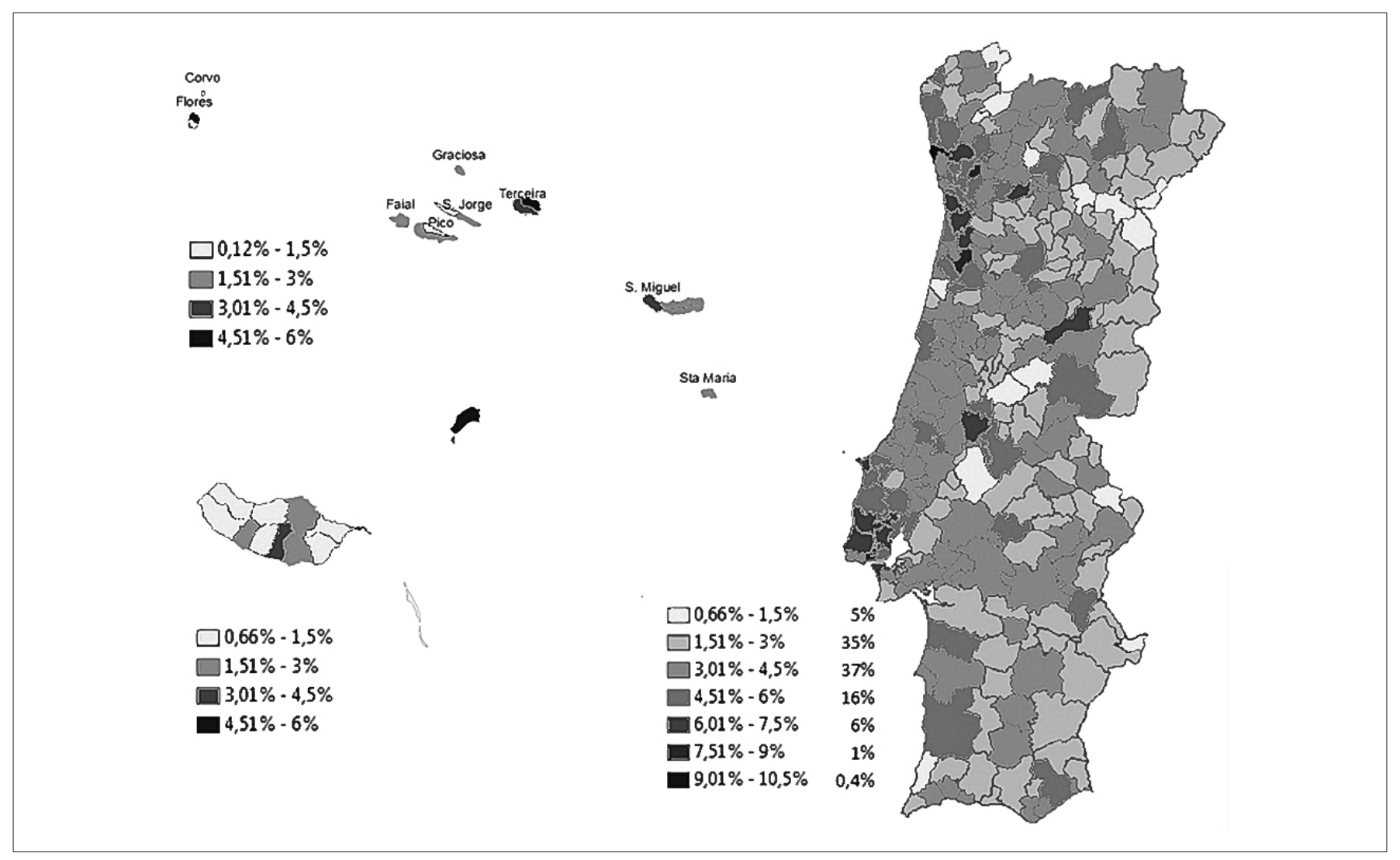

Figura 4 - Despesas com os Serviços de Água e de Esgotamento Sanitário das famílias portuguesas com rendimento igual ao salário mínimo nacional. 

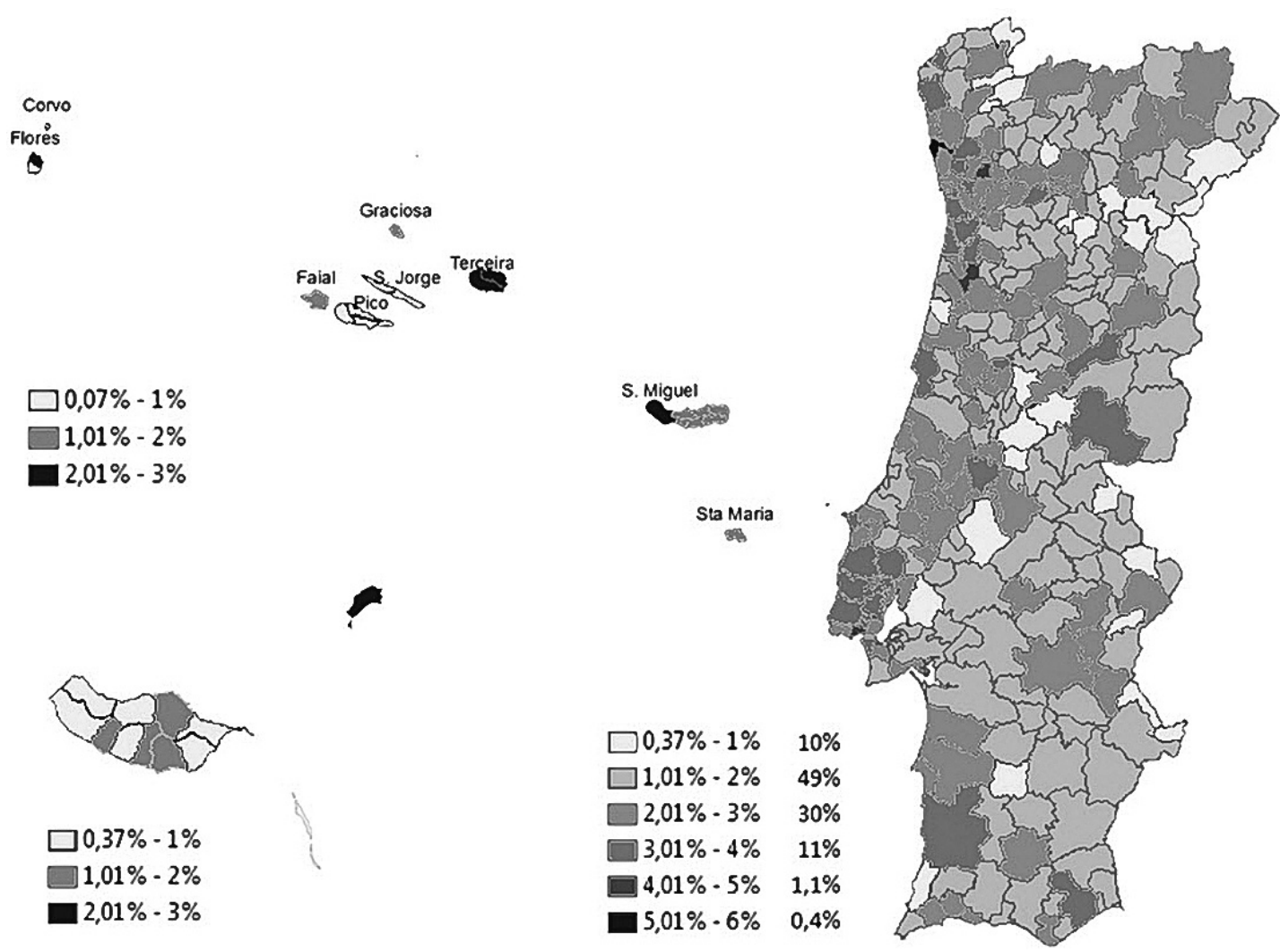

Figura 5 - Rendimento líquido dos agregados familiares constituídos apenas por um idoso gasto com os Serviços de Água e de Esgotamento Sanitário.

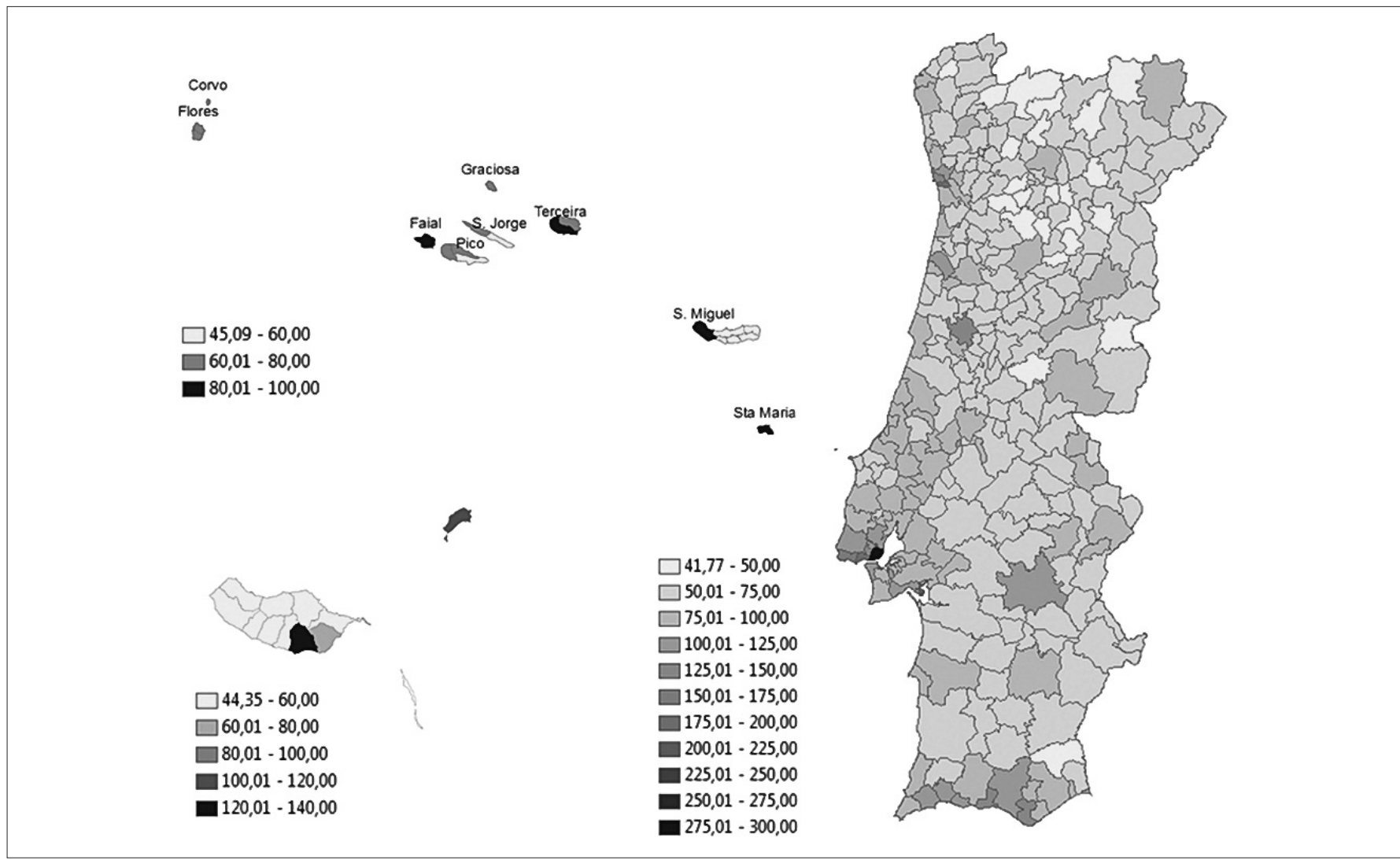

Figura 6 - Poder de compra médio em 2004 para os municípios. 


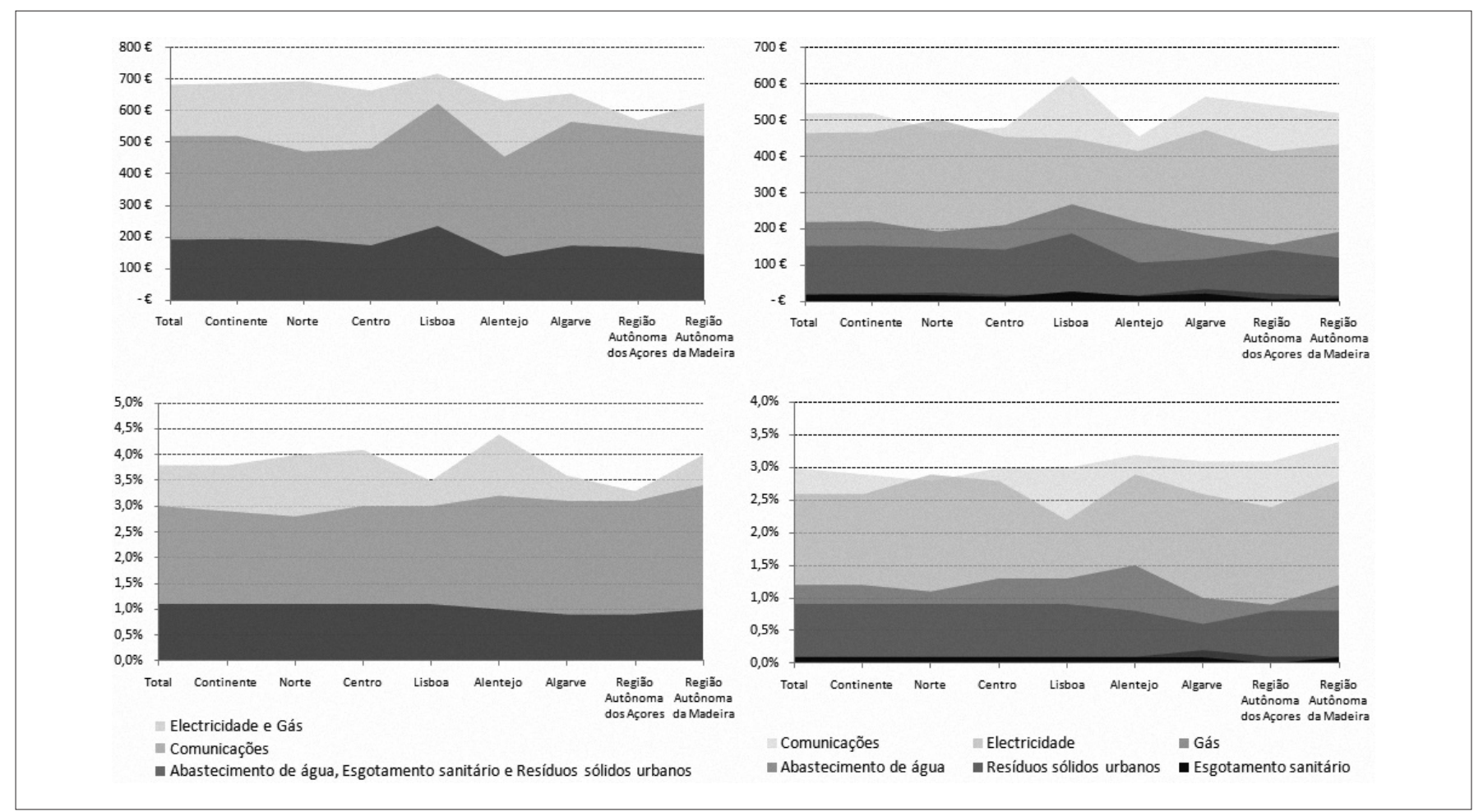

Figura 7 - Despesa total anual média por agregado com as faturas da água, eletricidade, gás e comunicações em 2005/2006 (INE, 2008).

dos serviços de lazer, cultura e ensino, comparativamente às restantes regiões) e de existirem menos despesas nessas atividades no Alentejo.

Refira-se, por último, que em Portugal vários SAES têm implementado tarifas sociais, quer para famílias numerosas (uma vez que o tarifário é sempre bipartido por escalões crescentes com o consumo), quer para consumidores com rendimentos reduzidos. Essas tarifas sociais são tarifários de menor custo para permitirem a fácil acessibilidade aos serviços de água pelas famílias mais desfavorecidas (por exemplo, usuários desempregados de longa duração ou com doenças crónicas) ou com um agregado familiar elevado (isto é, três ou mais filhos). Os consumidores com maiores consumos e, em particular, os não domésticos industriais subsidiam os consumidores domésticos. Os encargos com o serviço de abastecimento de água subsidiam, ainda, os serviços de esgotamento sanitário e a recolha e tratamento de resíduos sólidos urbanos.

\section{Conclusões}

Em Portugal, a generalidade das tarifas praticadas pelos SAES não possibilitam ainda a recuperação dos custos associados ao fornecimento dos serviços. Antevê-se que, num futuro próximo, esse quadro seja bem diferente. Com a publicação da Lei da Água, os preços dos SAES devem respeitar os princípios do seu valor social, da dimensão ambiental e do valor econômico da água e as futuras tarifas. Além de assegurarem a recuperação dos custos de investimento e de operação dos serviços, terão ainda de incorporar uma componente relativa às taxas de utilização dos recursos hídricos, incluindo os princípios do "utilizador-pagador" e do "poluidor-pagador".
Desse modo, avizinha-se um aumento do preço desse recurso e, consequentemente, uma maior parcela dos rendimentos familiares será dispensada para os SAES. Os resultados do presente estudo demonstram que, em 2004, as famílias portuguesas gastavam uma maior percentagem dos seus rendimentos com os SAES, grosso modo, nos municípios mais próximos do litoral do país, e uma menor percentagem dos seus rendimentos nos municípios situados mais no interior, evidenciando que os problemas de affordability eram maiores no litoral. Esse fato poderá indiciar que é no interior do país que os consumidores pagam um preço político pelos serviços, em especial em relação aos serviços de esgotamento sanitário. Se for considerado que o poder de compra era menor nos municípios do interior, em particular nos do interior norte, e que essa distribuição se manterá futuramente, poderá prever-se uma inversão do cenário atual e, provavelmente, será no interior do país que poderão vir a surgir os maiores problemas de affordability.

Ademais, considerando-se que, em 2005, 19\% da população residente em Portugal se encontrava em situação de risco de pobreza, os problemas de affordability poderão agravar-se ainda mais, em especial para os agregados familiares constituídos apenas por um idoso e para as famílias com dois adultos e três ou mais crianças dependentes, os quais constituíam os grupos com a taxa mais elevada de risco de pobreza, representando $8 \%$ dessa população.

Toda essa conjuntura, para além das consequências que terá sobre os consumidores, poderá conduzir ainda, num futuro próximo, a uma diminuição do consumo por parte das famílias de menores recursos, dado que os consumidores em Portugal, tal como globalmente, parecem ser sensíveis ao aumento de preço dos serviços. De qualquer 
forma, dada a inelasticidade desse bem (pela sua indispensabilidade), a redução será sempre pequena, pelo menos para os consumos essenciais. Refira-se também que, apesar de elevadas, as parcelas dos rendimentos das famílias gastas com os SAES em 2004 encontravam-se dentro de limites aceitáveis quando comparadas aos valores verificados em outros países, bem como aos indicados pela OCDE.

Por último, saliente-se que importantes consequências do ponto de vista regulatório e do governo do setor podem ser obtidas com estudos desta natureza. Em particular, a estrutura do sistema tarifário, o tipo de usuários e de consumos, a existência de tarifas sociais e as políticas de subsidiação cruzada devem estar dependentes da affordability dos consumidores. Em Portugal, os dois estudos referidos foram importantes para documentação e normalização produzida recentemente pelo regulador sobre essas matérias (IRAR, 2009).

\section{Agradecimentos}

Os autores manifestam a sua gratidão aos dois revisores anónimos, cujos comentários, sugestões e críticas permitiram melhorar substancialmente o artigo final.

\section{Referências}

ASSOCIAÇÃO PORTUGUESA DE DISTRIBUIÇÃO E DRENAGEM DE ÁGUA (APDA). Água e saneamento em Portugal - o mercado e os preços. Lisboa: Comissão Especializada de Legislação e Economia, Associação Portuguesa de Distribuição e Drenagem de Água, 2006.

BANCO MUNDIAL. Banco Mundial: oportunidades para empresas portuguesas. Disponível em: http://siteresources.worldbank.org/ INTEDS21/Resources/Newsletter_2_Sector_G_R_Hidricos.pdf. Acesso em: 22 nov. 2010. n. 2. Washington D.C.: Banco Mundial, 2006, p. $1-11$.

CONGRESSIONAL BUDGET OFFICE (CBO). Future investment in drinking water and wastewater infrastructure. Washington D.C.: Congressional Budget Office, 2002.

DANESI, L.; PASSARELLI, M.; PERUZZI, P. Water services reform in Italy: its impacts on regulation, investment and affordability. Water Policy, v. 9, n. 1, p. 33-54, 2007.

DEPARTMENT FOR ENVIRONMENT, FOOD AND RURAL AFFAIRS (DEFRA). Cross-government review of water affordability report. London: Department for Environment, Food and Rural Affairs; 2004

FANKHAUSER, S.; TEPIC, S. Can poor consumers pay for energy and water? An affordability analysis for transition countries. Energy Policy, v. 35 n. 2, p. 1038-1049, 2007.

INSTITUTO NACIONAL DE ESTATÍSTICA (INE). Dia Internacional de Erradicação da Pobreza: 17 de Outubro. A População Residente em Situação de Risco de Pobreza era de 19\% em 2005. Lisboa: Instituto Nacional de Estatística, 2007, p. 1-7.

Inquérito às Despesas das Familias 2005-2006. Lisboa: Instituto Nacional de Estatística, 2008.

Orçamentos Familiares 2005/2006. Habitação e Produtos Alimentares Representavam 42\% das Despesas dos Agregados Familiares em 2005/2006. Lisboa: Instituto Nacional de Estatística, 2008, p. 6-20.

INSTITUTO REGULADOR DE ÁGUAS E RESÍDUOS (IRAR). Percepção pública e disponibilidade para pagar por melhorias na qualidade dos serviços de águas e resíduos em Portugal Continental. Lisboa: Instituto
Regulador de Águas e Resíduos, 2007a.

RASARP 2006 - Relatório Anual do Sector de Águas e Resíduos em Portugal. Volume 1: caracterização geral do sector. Lisboa: Instituto Regulador de Águas e Resíduos, 2007b.

Recomendação IRAR n. 01/2009. Recomendação Tarifária. Lisboa: Instituto Regulador de Águas e Resíduos, 2009.

JONES, A. et al. A qualitative exploration of the public perception of municipal drinking water. Water Policy, v. 9, n. 4, p. 425-438, 2007.

MARQUES, R.C. Regulação de Serviços Públicos. Lisboa: Edições Sílabo, 2005.

The yardstick competition regulatory model: discussing the Portuguese experience. Water Science and Technology: Water Supply, v 8, n. 5, p. 541-549, 2008

MARQUES, R.C.; LEVY, J.Q. A qualidade do serviço de abastecimento de água. O parecer do consumidor. Lisboa: Associação das Empresas Portuguesas para o Sector do Ambiente, 2006.

MARQUES, R.C.; SIMÕES, P. Does the sunshine regulatory approach work? Governance and regulation model of the urban waste services in Portugal. Resources, Conservation \& Recycling, v. 52, n. 8/9, p. 1040-1049, 2008.

Organização para a Cooperação e Desenvolvimento Económico (OCDE). Social Issues in the Provision and Pricing of Water Services. Paris: Organização para a Cooperação e Desenvolvimento Económico, 2002.

PROGRAMA DAS NAÇÕES UNIDAS PARA O DESENVOLVIMENTO (PNUD). Relatório do desenvolvimento humano 2006. A água para lá da escassez: poder, pobreza e a crise mundial da água. Nova York: Programa das Nações Unidas para o Desenvolvimento, 2006.

SMETS, H. Quantifying affordability of water supply and sanitation. In: INTERNATIONAL CONFERENCE ON THE RIGHT TO WATER AND SANITATION IN THEORY AND PRACTICE, Oslo, Norway, 2008.

WORLD HEALTH ORGANIZATION (WHO). Meeting the MDG drinking water and sanitation target: the urban and rural challenge of the decade. Geneva: World Health Organization, 2006. 